\title{
EXPLORING GENDER STEREOTYPES IN MEDIA ADVERTS: A MULTIMODAL ANALYSIS
}

\author{
Tazanfal Tehseem \\ Masroor Sibtain $^{* *}$ \\ Zara Obaid $^{* * * *}$
}

\begin{abstract}
This paper aims at identifying socio-cultural portrayal of women through representational, interactive and compositional meanings with a focus on gender stereotypes propagated by media advertisements in Pakistan. Media adverts as such are an instrumental tool for manipulating attitudes and behavior of large and diverse audience for example, a large body of data reveals that women are portrayed in media to stylize their physical attributes to tempt and persuade customers. Therefore, advertisements are instrumental in creating a certain mind-set by shaping an ideology through highlighting the hegemonic representation of men and sexual objectification of women for creating an erotic fantasy. The data for the study comprises print media adverts which were randomly collected to have primarily advertised Pakistan TV morning shows, home products and cosmetics and have been selected on an assumption that they embody a socio-cultural perspective. The findings show that the selected adverts project the world of male chauvinism where women are shown as the facilitating sexual objects.
\end{abstract}

Keywords: Media adverts, multimodal discourse analysis, hegemonic ideology, and sexual objectification

\section{Introduction}

This research explores Pakistani advertisements being used as a medium for defining gender roles in society. It particularly analyzes the aspect of sexual objectification of women in adverts where women are used as a commodity to increase the appeal of a product, or as subservient to men. The study is significant in identifying what major semiotic resource systems Pakistani advertisers deploy for disseminating a particular ideology and enhancing stereotypical representation of women in Pakistan.

In this global world where everything has come close owing to the technology, socialization has also become rapid due to the far reaching effects of mass media. Advertising; therefore, has become one of the most powerful agents for socialization in this modern world. It helps us to construct certain ideologies and behaviors and develop

* Tazanfal Tehseem, Assistant Professor, Department of English, University of Sargodha

** Maroor Sibtain, Ph.D. Assistant Professor, Department of English, Government Postgraduate Emerson College, Multan

*** Zara Obaid, Research Scholar, Department of English, University of Sargodha 
certain social constructs such as gender. Gender is the role we play in a society and not the biological sex with which we are born. Advertising plays a major role in attributing biological sex with particular gender roles; hence, contributing in gender socialization.

Gender advertisements are one particular genre of advertising which portray the stereotypical gender roles to juxtapose men and women in particular societal constructs. These roles are then taken up by the society as a part of process of socialization. Among the accepted gender roles are masculinity and femininity with the former usually related to men and the latter to women, except a few advertisements in niche marketing where the roles are often reversed.

As the discourse of advertisements takes its shape through language as well as images, a multimodal discourse analysis approach proposed by Kress and Van Leeuwen $(1996)^{1}$ is used to analyze the advertisements. This research will analyze different multimodal elements which create gender distinction in these adverts. It will also explore what modes are more frequently employed for the stereotypical representation of women in adverts.

Therefore, this research aims to address the following research questions:

- What combinations of modes are employed for representing women in adverts?

- How language is combined with women images in complex texts to construct implicit reality?

- Which cultural, conventional or social elements enhance multimodal representation of women in Pakistan?

\section{Review of the Related Literature}

Advertising is a vital part of our daily life and no one can escape its influence. It surrounds us by means of newspaper, magazines, the internet and TV etc. Advertisements are the most influential tool for creating stereotypes in any society. According to Grammer, "ads sell a great deal more than products. They sell values, images, and concepts of success and worth, love, sexuality" $(1998,219-240) .^{2}$ Therefore, this study will analyze the stereotypes created and sold by Pakistani advertisements.

Gender studies started with a rise against male chauvinistic society and a bend towards feminism. Since then, the work in this field is expanding in various fields of life, one of them being advertisements. According to Lewis "feminists have been highly critical of advertising...which [normalize] particular images of svelte, youthful, thin female bodies". ${ }^{3}$ Money and Ehrhardt used the term sex to refer to the biological classification of

\footnotetext{
${ }^{1}$ Kress, Gunther R., and Theo Van Leeuwen. Reading images: The grammar of visual design. London: Routledge, 1996.

${ }^{2}$ Grammer, Karl. "Sex and gender in advertisements." In Ethnic conflict and indoctrination: Altruism and identity in evolutionary perspective, edited by Irenäus Eibl-Eibesfeldt, Frank K. Salter, 219-240. New York: Berghahn Books, 1998.

${ }^{3}$ Ullah, Hazir. \& Hifsa Nisar Khan. "The objectification of women in television advertisements in Pakistan." In FWU Journal of Social Sciences, 8(2), 26-35, 2014.
} 
male/female and gender to refer to differences in behavior by sex. ${ }^{4}$ Hence, this study will explore the gender stereotypes and their role in society developed by adverts.

Advertisements play a crucial role in stereotyping genders by creating a gender gap. Bardwick and Schumann analyzed role portrayals of men and women in television commercials and proved that women are portrayed primarily as homebound. ${ }^{5}$ Goffman also shed light on gender stereotypes in advertisements. ${ }^{6}$ He proved that in adverts men are portrayed as relatively greater in size compared to women, women more often are shown caressing objects, men are more often depicted with their bodies erect while women are shown leaning. So, he asserted that women are mostly shown dependent on their male counterparts and as subservient to them.

Grammar particularly focused on the concept of sexual objectification of women in advertisements $(1998,219-240) .{ }^{7}$ Courtney and Whipple defined sexual objects as, where women had no role in the advertisement, but appeared as an item of decoration (1974, p). ${ }^{8}$ According to Grammer, advertising play a vital role in indoctrination and claimed that it is responsible for projecting "women as sex symbols and as an inferior class of human being" (1998, 220). ${ }^{9}$ Contrarily, men in advertisements are presented as "dominant, prosperous, nurturant and of high social status". ${ }^{10}$ Similarly, Stankiewicz and Rosselli show that in magazines every one of two adverts featuring women portray them as sexual objects. Even the most recent researches show that despite a considerable change in our society that advocate a diversity in gender roles, advertisements still stick to the stereotyped roles for women. Collins and Zotos and Tsichla analyzed researches on gender roles in advertisements published over time, and found out that the trend of stereotypical gender representation is still alive. Women are still presented as sexualized and subordinated. Thus, there is no substantive change in the portrayal of women over years in advertisements.

A number of studies have also been conducted on Pakistani advertisements and their role in disseminating gender stereotypes. Studies conducted on only male stereotypes show that male representation in adverts still support the patriarchal fabric of the society. For example, more males are located in the workplace and more voiceovers are carried out by males (Mirza, 2015; Mirza \& Iftekhar, 2016). ${ }^{11}$ This shows that men are still given the

4 Money, John, and Anke A. Ehrhardt. Man and woman, boy and girl: The differentiation and dimorphism of gender identity from conception to maturity. Baltimore: John Hopkins University Press, 1972.

5 Bardwick, Judith M., and Suzanne I. Schumann. "Portrait of American men and women in TV commercials." In Psychology, 4(4), 18-23, 1967.

6 Goffman, Erving. Gender advertisements. New York: Harper and Row publishers, 1979.

7 Grammer, Karl. "Sex and gender in advertisements." In Ethnic conflict and indoctrination: Altruism and identity in evolutionary perspective, edited by Irenäus Eibl-Eibesfeldt, Frank K. Salter, 219-240. New York: Berghahn Books, 1998.

8 Courtney, Alice E., and Thomas W. Whipple. "Women in TV commercials.' Journal of Communication' 24 (2) 1974: 110-118

9 Grammer, Karl. "Sex and gender in advertisements." In Ethnic conflict and indoctrination: Altruism and identity in evolutionary perspective, edited by Irenäus Eibl-Eibesfeldt, Frank K. Salter, 219-240. New York: Berghahn Books, 1998.

${ }^{10}$ Ibid., 228

${ }^{11}$ Mirza, Zainab. K. "Male gender stereotypes in Pakistani advertisements". PEOPLE: International Journal of Social Sciences 2(1) 2015: 1716-1732. 
dominant and active part in the society. Contrarily, Ullah and Khan ${ }^{12}$ (2014) focused their study on women objectification and showed that television adverts idealize petite and delicate female bodies as feminine capital. Ali and Shahwar ${ }^{13}$ (2011) conducted their study on the representation of both men and women in Pakistani adverts and showed that a stereotypical image was created for both. For example, women were presented more as ornamental objects and less active in an advert and in limited occupations, while men were presented in a variety of occupations. The present study differs from all the previous researches in its methodology. All the researches under reference employed content analysis or critical discourse analysis. As an advertisement is a visual medium so an analysis of just the contents or information presented in an advert does not fulfill the purpose. A visual, in this case an advertisement, makes its first impression even before one reads its contents and it is the reason behind it is its layout, choice of colors, alignment of information, size of images and font of texts. In order to cater all these aspects for analysis, the methodology employed for this research is multimodal discourse analysis.

In this research a number of gender advertisements are analyzed with a multimodal approach. Multimodality is "the phenomenon in texts... whereby a variety of "semiotic modes' (means of expression) are integrated into a unified whole" (Van Leeuwen and Kress 2011, 107). ${ }^{14}$ This multimodal artifact is usually realized through more than one modes of communication i.e. some combination of language, image, spatial design, etc. (Martin and Rose 2008, p) ${ }^{15}$ When analyzing multimodal artifact, it is not only necessary to analyze the text, but also the visual 'input' (Bateman 2008, p). ${ }^{16}$ Therefore, this study will explore the gender stereotyping of represented participants, the one's presented in an advertisement, in Pakistani adverts through multimodal analysis.

\section{Research Methodology}

This research employs multimodal discourse analysis approach proposed by Kress and Van Leeuwen ${ }^{17}$ based on Systemic Functional Linguistics of Halliday. ${ }^{18}$

\section{Sample}

The sample taken for this research comprises of eight Pakistani advertisements sourced from the internet. They belong to a variety of categories in i.e. three drama adverts, four

Mirza, Zainab K. and Ifra Iftekhar. "Role of electronic media in preserving gender roles through advertisements". In Proceedings of 2nd International Multi-Disciplinary Conference. Gujrat: The University of Lahore, Gujrat Campus, 2016.

${ }^{12}$ Ullah, Hazir. \& Hifsa Nisar Khan. "The objectification of women in television advertisements in Pakistan." In FWU Journal of Social Sciences, 8(2), 26-35, 2014.

13 Ali, Shahzad and Deeba Shahwar. "Men, women and T.V. ads: The representation of men and women in the advertisements of Pakistani electronic media". Journal of Media and Communication Studies 3(4) 2011: 151159.

${ }^{14}$ Van Leeuwen, Theo, and Gunther Kress. 'Discourse semiotics", 2011, 107-125.

${ }^{15}$ Martin, James R. \& Rose, David. Genre relations: Mapping culture. London: Equino, 2008.

${ }^{16}$ Bateman, John. Multimodality and genre: A foundation for the systematic analysis of multimodal documents. Basingstoke: Palgrave Macmillan, 2008.

${ }^{17}$ Kress, Gunther R., and Theo Van Leeuwen. Reading images: The grammar of visual design, 2006.

${ }^{18}$ Halliday, Michael A K. Introduction to functional grammar, 2nd ed. London: Arnold, 1994. 
commercial adverts and one morning show advert. Commercial advertisements further comprise of a Cool Bank deep freezer, Huawei smart phone and Lux soap. Drama adverts consist of a poster of Pyaaray Afzal aired on ARY Digital, ZIP Bus Chup Raho and Aap ki Kaneez aired on Geo TV. The samples are representative of the aim and are selected through purposive sampling.

\section{Method of analysis}

It analyzes the advertisements through three metafunctions:
i. Representational meaning
ii. Interactive meaning
iii. Compositional meaning

\section{Representational meaning}

It refers to the content and potential ideas represented in a multimodal ensemble. ${ }^{19}$ Representational meaning is recognized by two processes; Narrative process and Conceptual process. Narrative process presents unfolding of actions and events through vectors. A vector is an imaginary line that connects participants with each other or participants with viewers. Narrative process has further two types; Action process and Reaction process. In an Action process, "the Actor is the participant from which the vector emanates, or which itself...forms the vector". ${ }^{20}$ If the image has only one participant, i.e. Actor; then, the process is called non-transactional action process as it has no Goal towards which something is directed. Conversely, if the image has two participants i.e. an Actor and a Goal, then the process is called transactional action process. Contrarily, Reaction process occurs "when the vector is formed by an eyeline". ${ }^{21}$ The represented participant who does the act of looking is called Reacter and the participant at which the Reacter is looking is called Phenomena. Moreover, reaction processes can also be transactional or non-transactional depending on the presence or absence of Phenomena respectively. The second type of Narrative process i.e. Conceptual process presents participants as more static giving them a timeless essence owing to the absence of vectors. It has further three types; Classificational process, Analytical process and Symbolic process. Classificational process relates participants to one another "in terms of a 'kind of' relation, a taxonomy". 22 Analytical process relates participants "in terms of a part-whole structure". ${ }^{23}$ It has two types of participants, i.e. Carrier which is the whole and its Possessive Attributes which are the parts. Lastly, symbolic process tells "what a participant means or $i s " .{ }^{24}$ It has further two types: Symbolic Attributive and Symbolic Suggestive. Symbolic Attributive process has two participants: the Carrier "whose meaning or identity is established in the relation" 25 and the Symbolic Attribute

19 Serafini, Frank. Reading the visual: An introduction to teaching multimodal literacy. New York: Teachers College Press, 2013.

${ }^{20}$ Kress, Gunther R., and Theo Van Leeuwen. Reading images: The grammar of visual design, $2006,63$.

${ }^{21}$ Ibid., 67.

22 Ibid., 79.

23 Ibid., 87

${ }^{24}$ Ibid., 105

25 Ibid., 93 
"which represents the meaning or identity itself". ${ }^{26}$ Symbolic attribute can be identified e.g. by being in foreground, being pointed at through a gesture etc. However, Symbolic Suggestive process has only one participant, i.e. Carrier whose meaning is established symbolically e.g. by realizing participants as silhouettes through extreme lighting etc.

\section{Interactive meaning}

It refers to the relationship between the represented participants and the viewers. ${ }^{27}$ Interactive meaning is analyzed through three dimensions; Contact, Size of frame and Perspective. Contact is determined by the presence or absence of gaze towards the viewer. If the gaze of participants is directed towards the viewer/camera creating an imaginary relation with the viewer; then, such an image is called demand picture. This is often supported by some sort of physical gesture like smile, pout or a stare. Such pictures call for the viewers to enter their world and identify with them. Contrarily, if gaze of the participants is directed away from the viewer/camera forming no imaginary relation with the viewers; then, such an image is called Offer picture. Represented participants in such an image are presented as objects of viewer's scrutiny and contemplation. The second dimension, size of frame determines the social distance between represented participants and viewers. Generally, three types of shots are used to represent participants. A close-up shot (head and shoulders) suggests an intimate relationship, a medium shot (waist) suggests social relationship while a long shot (full figure) implies the impersonal relationship between the represented participants and viewers. The third dimension, perspective explains the attitude towards represented participants. It is determined through different choices of horizontal and vertical angles. Horizontal angle can be frontal indicating inclusion or involvement or it can be oblique implying exclusion or detachment of viewers with the represented world. Vertical angle, contrarily, helps to establish the power relations between represented participants and viewers. Thus, if the subject is shot from a high angle with camera above the eye level; then, it makes the subject look small, weak and insignificant. If the subject is shot from a low angle with camera below the eye level; then, it makes it look bigger, imposing and powerful. Lastly, if the subject is shot from eye level angle; then, it suggests equality between represented participants and viewers.

\section{Compositional meaning}

It refers to the arrangement of different visual elements which helps to study image as a whole. There are three dimensions which are used to describe compositional meaning; Information value, Salience and Framing. Information value is determined by the layout and position of elements in different zones of an image which bestow them with different information values. Generally, there are three layouts which are followed; new-given, ideal-real and centre-margin. In new-given structure, the elements on the left side along horizontal axis or left elements in a centered composition establish that they are already known and familiar to the viewer, something well-established and self-evident, hence

\footnotetext{
${ }^{26}$ Ibid., 101

${ }^{27}$ Serafini, Frank. Reading the visual: An introduction to teaching multimodal literacy. New York: Teachers college press, 2013.
} 
called "given". While the elements on the right side or right elements in a centered composition establish that they are not yet known to the viewer and are thus surprising, so they need special attention, hence called "new". In the second layout i.e. ideal-real structure, the elements in the upper section imply power, high status, happiness, and all the basics associated with an ideal world (what might be), hence called "ideal". While the elements in the lower section propose depravity, low status, lack of power and all the basics associated with a real world (what is), hence called "real". According to third layout, centre-margin structure, the elements in the centre are considered as the nub of information while elements at the periphery being subservient and dependent upon the centre. The second aspect, salience is the degree to which an element draws attention to itself. It is controlled by various factors such as color, sharpness, tonal difference, relative size etc. The last aspect namely framing is a device that is used to connect or disconnect different elements from each other by the presence or absence of framing devices respectively. Framing devices can be frame lines, discontinuity of color and shape, space between elements etc.

In addition to visual analysis, language will also be analyzed in relation to images. So using this methodology, different media-adverts will be analyzed.

\section{Data Presentation and Analysis}

This research is conducted on Pakistani advertisements contained in Appendix A. Each advertisement is analyzed individually through multimodal discourse analysis approach.

\section{Analysis of the Advert 'Pyaary Afzal' (fig: 4.1)}

\section{Visual Analysis}

\section{Representational Meaning}

This narrative discourse constructs the world of male chauvinism where women are shown as the facilitating sexual objects. There are four represented participants in this poster, one male and three females suggesting male as centre of attention, and females shown as facilitating objects. The representational meaning comprises of four Reaction processes, one transactional and three non-transactional processes. Transactional process comprises of the female lead (on extreme left) acting as Reacter directing her gaze in a very exotic manner on the male character who acts as Phenomena. The other three Reaction processes (non-transactional) are formed by the remaining three characters (one male and two females) with their eye lines towards viewers. Here, the Reactors are the characters and no Phenomena are represented.

\section{Interactive Meaning}

There is a direct gaze by left three participants; thus, establishing a relationship with the viewers. It forms a Demand picture. However, gaze of one female participant (extreme right) forms an Offer picture as it is directed away from the viewers. Concerning size of frame, the participants are taken in a close shot, up to shoulders. So distance is close thus showing very intimate relationship. Considering perspective, horizontal angle of male 
participant is frontal whereas that of all female participants is slightly oblique. It shows their detachment from the world but attachment with the male represented participant. Lastly, vertical angle shows the relation of equality.

\section{Compositional Meaning}

Concerning information value, centre-margin structure is adopted. In this poster, the male participant present in the foreground is represented as a dominant Centre while other women participants present in the background are presented as subsidiary and subservient objects. Speaking of salience, the four represented participants are the salient part in the whole poster with male participant being most salient due to the highly saturated and dark color of his clothes and comparatively large size of image; drawing attention towards the world of male chauvinistic society. Considering framing, there is no dividing line between the represented participants which shows the intimacy and connection between characters.

\section{Textual Analysis}

This poster reads "Pyaray Afzal" in Urdu which can be translated as "Dear Afzal". It is a relational attributive process with "Afzal" being the carrier and "Dear" is the attribute. As Afzal is the hero so "Dear" is used to further glorify his character. The mood of this sentence is imperative. It is actually addressing "Afzal" the hero but in a polite manner which gives it a shade of request. So, it further highlights the male dominance. The title "Dear Afzal" is used to elevate the character of the only hero in the poster. Although there are three other female characters in the poster yet the title names hero only, and gives no hint of presence of female characters; thus portraying them as subservient to the male character.

\section{Analysis of the "Morning Shows' Advert (fig: 4.2)}

\section{Visual Analysis}

\section{Representational Meaning}

This Conceptual media discourse constructs the world of female portrayal in the capacity of sexual entities. It forms a Classificational process as all the five participants share a kind of relation of being portrayed in a similar manner i.e. objectified. Also, it has a "symmetrical composition" 28 i.e. images are at equal distance and of the same size which is characteristic of classificational process. This conceptual discourse highlights the timeless essence of these beauties as they are placed against a plain background; thus, giving them a more erotic look. The first participant from the left carries a smile on her face and makes a direct contact with lens of the camera while the next three participants apart from making a direct gaze have their lips slightly apart to give a lusty look. Similarly, the participant on extreme right exposes her skin by raising her chin and gives a tempting gaze.

${ }^{28}$ Kress, Gunther R., and Theo Van Leeuwen. Reading images: The grammar of visual design, 2006, 79. 


\section{Interactive Meaning}

There is a direct lusty and tempting gaze. The gaze is of Demand, and seduces the viewer to enter their world and join them. Also, it is a close shot offering very intimate relationship. Horizontal angle is frontal of the left most represented participant whereas rest of the four represented participants have a slightly oblique angle which presents them as commodities. Vertical angle, in comparison, shows the relation of equality being shot from an eye level angle.

\section{Compositional Meaning}

Considering information value, centre-margin structure is adopted. All the five represented participants are identical in this centered composition so it creates symmetry. As far as ideal-real structure is concerned, the images being in the upper section of the poster indicate the idealization of these beauties to attract the audience while the written text in the lower section emphasizes on the reality of their portrayal who in actual are just used as sex objects. Moreover, the five female participants are the most salient part in the whole poster attracting viewers. Lastly, there are frame lines between the five participants suggesting disconnection between them because they are five different morning show hosts.

\section{Textual Analysis}

The poster reads "Pakistani morning TV shows? What culture do they represent?" The mood of the sentence is indicative asking a question in a sarcastic tone. The statement has a big question mark in front of it which adds intonation. Its bigger font highlights the cultural constraints of our society. Similarly, "Pakistani" has a relatively larger font and has a darker tone of pink color as compared to other words which puts an extra emphasis on it highlighting the fact that Pakistani culture, unlike this presentation, does not endorse presentation of women in an explicit way.

Analysis of the “Cool Bank Deep Freezer' Advert (fig: 4.3)

\section{Visual Analysis}

\section{Representational Meaning}

This advert builds the field commercial activity of consumer-ship of a deep freezer where a young girl is shown as a persuasion strategy. The represented participant in the poster creates a conceptual discourse comprising of a Symbolic Attributive process. The deep freezer in this image acts as a Carrier whereas female participant acts as a Symbolic Attribute because she is in the foreground. The Symbolic Attribute in this image looks appealing owing to her projection as a sexual object, directing smile at the viewers and sitting in a tempting manner. These qualities of the Symbolic Attribute are then ultimately conferred to the deep freezer to make it look appealing and attractive to the viewers; hence, catching their attention. Thus, the represented participant in this poster is a woman portrayed as an assisting sexual object for the sale of a deep freezer. 


\section{Interactive Meaning}

As far as contact is concerned, a direct tempting and erotic look, and smile attract the customers. The gaze of the participant suggests Demand and invites the viewer to enjoy the product and its benefits. Besides, it is a long shot suggesting an impersonal relation between her and viewers. With a deep freezer in background; however, it suggests the social business of consumer-ship of deep freezer. Moreover, horizontal angle is frontal which shows attachment of represented participant with viewers calling their attention while vertical angle shows the relation of stereotype portrayal being shot from eye level angle.

\section{Compositional Meaning}

Concerning information value, ideal-real structure is adopted. The text in the upper portion "Cool Bank- a solution to load-shedding" is being idealized to attract the attention of viewers owing to the circumstances of the country i.e. power cut. In the lower section (Real) the female participant is presented as a centre showing sexual projection with one leg open. Deep freezer on its left (Given) shows that it is something already familiar to the viewers, and viewers can rely on its reliability while the text on the right (New) of female participant "Buying Cool Bank is intelligence" shows that it is something that is not yet agreed upon by viewers, so it is something contestable that will only become known if they buy the deep freezer. Therefore, the lower section is real because it shows a typical so-called social construction. Moreover, the female participant in the whole poster is most salient trying to attract the viewers to buy her product. Furthermore, a framing device of color transition is used to divide the poster into ideal and real parts.

\section{Textual Analysis}

This poster has two tag lines. One is "Cool Bank- a solution to load-shedding", and the other is "Buying Cool Bank is intelligence". These tag lines have an indicative mood with an assertive tone. The latter tag line associates the word "intelligence" with the women presented in an exotic manner in the advertisement. So, woman is used as a facilitating sexual object for the sale of the product.

Analysis of the Zip Poster- 'Bus Chup Raho' (fig: 4.4)

\section{Visual Analysis}

\section{Representational Meaning}

This conceptual representation consists of Analytical process with the female participant being the Carrier whose identity is constructed in terms of Possessive Attributes like tattoo and a curvilinear body which highlight that she is exposed sexually. The lady in the poster has a tempting look on her face with lips slightly apart and her gaze directed in a very erotic manner. Moreover, the lady is touching and caressing her body which is also a sign of sexuality, and also lying on a couch making her look more vulnerable. 


\section{Interactive Meaning}

The participant has a Demand gaze which creates a relation with the viewer and invites him to enter her world. Further, this is a medium close shot which suggests some sort of public business between her and viewers making her available to audience. Considering perspective, horizontal angle is oblique which tells about the depth of character. Purple color which she is wearing also symbolizes mysteriousness. Moreover, the dark background also highlights her mysterious nature producing an urge in viewers to explore her. Vertical angle makes her look grand and imposing being shot from a low angle.

\section{Compositional Meaning}

This poster forms an ideal-real structure. The female represented participant in the lower section (Real) indicates that she is subject to control and can be easily accessed. Similarly, she is the most salient part in the whole poster against the dark background drawing attention to her. Moreover, framing device of color is used to separate image from text.

\section{Textual Analysis}

The text on this poster reads "zip, bus chup raho" in Urdu, which can be translated into English as "zip, just keep quiet". This is an imperative statement which suggests command. In this poster the word "zip" is written on a lip which implies the zipping of mouth. Further "just keep quiet" adds to the meaning and signals a command to the woman to keep quiet regarding her sexual exploitation (as her image represents). This again shows the subservience of woman. It also indicates that the function of women is just to look good and appealing with no attention to her words or thoughts.

\section{Analysis of the 'Lux Advert' (fig: 4.5)}

\section{Visual Analysis}

\section{Representational Meaning}

This narrative discourse comprises of a Reaction transactional process with the male participant being the Reacter and female participant being the Phenomena and vice versa. The female participant is directing her gaze back at the male participant in an erotic manner with a smile on her face. Furthermore, she is touching herself indicating sexuality with the pink color adding femininity, charm and tenderness.

\section{Interactive Meaning}

Considering gaze, this is an Offer picture with participants directing gaze towards each other and not the viewer. This shows that the couple is indifferent to audience and is object of viewer's scrutiny. So, this shows the intimacy between the two participants. Also, a close-up shot is used which suggests the intimate and personal relation between the two. Moreover, horizontal angle is oblique which expresses detachment from the world whereas vertical angle shows dominance of male character over female participant. 
Male participant is located higher than female participant which reflects the subordination of woman to the male.

\section{Compositional Meaning}

This poster forms an ideal-real structure. The text "just a little lux" is written in upper (Ideal) portion to idealize the product while the represented participants in the lower section imply that they are near reality. Male participant is on left side (Given) while the female participant on the right (New) implies that she is something on which viewer should pay special attention. Also, female participant is the most salient in the whole poster due to the bright pink color she is wearing. The female participant being dressed up in a lighter color against a dark background with male participant also dressed in dark color (black), catches the attention of viewer. Moreover, a line in the background is used as a framing device.

\section{Textual Analysis}

This poster reads "kashish barhti jaey with irresistibly soft fragrant skin" which can be translated as "Attraction grows with irresistibly soft fragrant skin". This sentence has an indicative mood with an assertive statement. In this sentence, the word "irresistibility" is used to intensify tempt for the body of woman. It is further strengthened by the image of a woman caressing her.

\section{Analysis of the 'Huawei' Advert (fig: 4.6)}

\section{Visual Analysis}

\section{Representational Meaning}

This conceptual representation comprise of Symbolic Attributive process. The female participant in this poster acts as a Carrier whereas the smart phone in her hand acts as a Symbolic Attribute because it is in the foreground. This smart phone which is smart in its outlook confers this attribute to the female participant as well; thus, establishes its identity as smart and beautiful. The female participant is directing her gaze in a very tempting manner with lips slightly apart giving her an erotic look. So, she is being used as a sexual object for the sale of the product which she is carrying in her hand.

\section{Interactive Meaning}

The participant forms a Demand picture with gaze directed at the viewers' making an imaginary relation with them. This enticing gaze invites the viewer to come and enjoy the product. Also, this is a close-up shot indicating personal and intimate relationship between represented participant and viewers. Similarly, horizontal angle is frontal which shows the involvement and intimacy between represented participant and viewers. Vertical angle implies the equality between participant and viewers shot from an eye level. This again shows the intimacy between participant and viewers, and suggests the ease with which viewer can enter her world. 


\section{Compositional Meaning}

This poster follows the given-new structure. The female participant on the left (Given) implies that the viewer is already familiar with her and can relate to her; thus, implying the intimacy between the two. Contrarily, the product (mobile) is placed on the right (New) because it is not yet familiar to the viewers and need to be contemplated. Moreover, the female participant is the most salient in the poster due to the large size of her image as well as the color contrast between the clothes she is wearing and the background. Framing devices of color and shape discontinuity are used to divide the poster in given and new portions.

\section{Textual Analysis}

This poster reads "a smart choice". It has an indicative mood. This poster is making a statement about the smartness of phone and intensifying this claim with the help of a female model who is smart, attractive and eye-catching for the audience. So, it intensifies the portrayal of women as a sexual commodity.

\section{Analysis of the Advert of 'Ap ki Kaneez' (fig: 4.7)}

\section{Visual Analysis}

\section{Representational Meaning}

This narrative representation presents woman as subservient to man. It comprises of a Reaction non-transactional process. The Reacter in this poster is the male participant who is directing his gaze towards the newspaper and partly downwards towards the female while female participant is the Phenomena. The newspaper in the hands of male participant seated in a chair gives him a bossy look and makes him a dominating figure whereas woman sitting on the floor, lower to the male figure, makes her subservient.

\section{Interactive Meaning}

The participants form an Offer picture as they are directing their gaze away from the viewer and acting as objects of contemplation for the viewers. Also, it is a long shot which shows the impersonal relationship between represented participants and the viewers. Likewise, horizontal angle is oblique which shows detachment from viewers whereas vertical angle shows the relation of dominance as man is seated above the woman.

\section{Compositional Meaning}

This poster follows given-new structure. The male participant on the right implies that viewer is already familiar with him while the female participant on the left implies that she is not familiar to the viewers and should be given special attention. Moreover, the male figure is the most dominant in the whole poster owing to his relatively large image size which shows his dominance over woman. Framing devices of lines are used to separate images from the written text. 


\section{Textual Analysis}

This poster reads "Ap ki kaneez" which means "Your servant (or maid)". It has an indicative mood. This statement asserts that woman is being considered subordinate to man as the word "servant" is used for her. Furthermore, as she is sitting on the floor and male figure is seated in a chair, so the word "servant" further asserts its meaning.

\section{Results and Discussion}

This section will quantify the results of analysis presented in the previous section in the form of a table and discuss it in detail. Analysis of samples prove that all the modes of meaning-making i.e. visual as well as verbal contribute to objectify women in advertisements.

Table: 1

Raw frequencies and percentages of representational, interactional and compositional meaning

\begin{tabular}{|c|c|c|c|c|c|c|c|}
\hline Sr. & \multicolumn{4}{|l|}{ Type } & \multirow{2}{*}{$\begin{array}{l}\text { Raw } \\
\text { Freq. } \\
0\end{array}$} & \multicolumn{2}{|c|}{ Percentage } \\
\hline \multirow[t]{8}{*}{1.} & \multirow{8}{*}{$\begin{array}{l}\text { Representation } \\
\text { al meaning }\end{array}$} & \multirow{4}{*}{$\begin{array}{l}\text { Narrative } \\
\text { process }\end{array}$} & Action & Transactional & & 0 & \multirow{4}{*}{63} \\
\hline & & & & $\begin{array}{l}\text { Non- } \\
\text { transactional }\end{array}$ & 0 & 0 & \\
\hline & & & \multirow[t]{2}{*}{ Reaction } & Transactional & 3 & 27 & \\
\hline & & & & $\begin{array}{l}\text { Non- } \\
\text { transactional }\end{array}$ & 4 & 36 & \\
\hline & & \multirow{4}{*}{$\begin{array}{l}\text { Conceptual } \\
\text { process }\end{array}$} & \multicolumn{2}{|c|}{ Classificational } & 1 & 9 & \multirow{4}{*}{36} \\
\hline & & & Analytical & & 1 & 9 & \\
\hline & & & \multirow[t]{2}{*}{ Symbolic } & $\begin{array}{l}\text { Symbolic } \\
\text { attributive }\end{array}$ & 2 & 18 & \\
\hline & & & & $\begin{array}{l}\text { Symbolic } \\
\text { suggestive }\end{array}$ & 0 & 0 & \\
\hline \multirow[t]{13}{*}{2.} & \multirow{13}{*}{$\begin{array}{l}\text { Interactional } \\
\text { meaning }\end{array}$} & \multirow[t]{2}{*}{ Gaze } & \multicolumn{2}{|l|}{ Offer } & 3 & & 30 \\
\hline & & & \multicolumn{2}{|l|}{ Demand } & 7 & & 70 \\
\hline & & \multirow{5}{*}{$\begin{array}{l}\text { Size of } \\
\text { frame }\end{array}$} & \multicolumn{2}{|l|}{ Close } & 4 & & 57 \\
\hline & & & \multicolumn{2}{|l|}{ Medium } & 0 & & 0 \\
\hline & & & \multicolumn{2}{|c|}{ Medium close } & 1 & & 14 \\
\hline & & & \multicolumn{2}{|c|}{ Medium long } & 0 & & 0 \\
\hline & & & \multicolumn{2}{|l|}{ Long } & 2 & & 29 \\
\hline & & \multirow[t]{6}{*}{ Perspective } & \multirow{3}{*}{$\begin{array}{l}\text { Horizont } \\
\text { al angle }\end{array}$} & Oblique & 3 & & 21 \\
\hline & & & & Slightly oblique & 7 & & 50 \\
\hline & & & & Frontal & 4 & & 29 \\
\hline & & & \multirow{3}{*}{$\begin{array}{l}\text { Vertical } \\
\text { angle }\end{array}$} & High level & 0 & & 0 \\
\hline & & & & Low level & 3 & & 43 \\
\hline & & & & Eye level & 4 & & 57 \\
\hline 3. & Compositional & Informatio & \multicolumn{2}{|l|}{ Ideal-real } & 4 & & 40 \\
\hline
\end{tabular}




\begin{tabular}{|c|c|c|c|c|}
\hline \multirow[t]{11}{*}{ meaning } & \multirow[t]{2}{*}{$\mathrm{n}$ value } & Given-new & 3 & 30 \\
\hline & & Centre-margin & 3 & 30 \\
\hline & \multirow[t]{4}{*}{ Salience } & Color & 4 & 44 \\
\hline & & Sharpness & 0 & 0 \\
\hline & & Tonal difference & 0 & 0 \\
\hline & & Relative size & 5 & 56 \\
\hline & \multirow{5}{*}{$\begin{array}{l}\text { Framing } \\
\text { devices }\end{array}$} & Frame lines & 1 & 12 \\
\hline & & Line & 2 & 25 \\
\hline & & Framing device of color & 3 & 38 \\
\hline & & No framing device & 1 & 12 \\
\hline & & Shape discontinuity & 1 & 12 \\
\hline
\end{tabular}

Table 1 shows that advertisers employ more narrative process to depict female participants. The reason is that narrative process uses vectors. Vectors depict participants as involved in some action. In the samples, it can be noticed that gaze is used as a vector in order to present participants in a provocative manner and sexually objectify them as well as to engage with readers.

The results also show that in adverts more images form a demand picture through their gaze. Again, the reason is that through demand picture, participants not only direct an erotic gaze that sexually objectify them, but also entices readers to buy their product. Contrarily, offer pictures simply present participants as sexual objects without any interaction with readers; therefore, media advertisements use less images with gaze directed away from viewers. Next, the findings of size of frame show that $57 \%$ of shots are close shots which present viewers and represented participants at a very intimate distance; thus, adding to their sexual objectification. Lastly, as per findings of vertical angle, $57 \%$ images use eye level angle and another $43 \%$ use low level angle to depict women in adverts. According to Kress and van Leeuwen, the use of low level angles in images "makes it look imposing and awesome". 29 This can be related to a recent wave of portrayal of women in adverts where women are presented as individuals "who choose to present themselves in a seemingly objectified manner". ${ }^{30}$ Hence, women depicted from a low level angle exhibit a power of being autonomous in their decision to be sexually objectified. Similarly, the use of eye level angle helps to give the impression of female participants being equal to the readers. It also represents females as being sovereign in their choice of being objectified. However, none of the images of women are presented from a high level angle i.e. as weak and powerless. This shift in trend presents sexual objectification of women from a new perspective.

Finally, the findings of compositional meaning show that for information value advertisers use more ideal-real structure in making the layout of advert. The analysis show that women in all the samples except one are presented in the lower i.e. Real section (e.g. sample 4.3 and 4.4) which shows that women are subject to power and

${ }^{29}$ Ibid., 140

${ }^{30}$ Gill, Rosalind. "Empowerment/sexism: Figuring female sexual agency in contemporary advertising.", Feminism and Psychology 18(1), 2008: 35-60. 
control and can be treated as a sexual commodity. Next, for salience, it is noticed that in adverts where images of both men and women are used as represented participants, men are always presented with a relatively large size and higher position as compared to women. For example in sample 4.7, the male participant is not only seated on a chair but also has a relatively large image size. The placement of male participants at higher position symbolize "high social place" (Goffman 1979, 43) ${ }^{31}$ and relatively large image size is associated with "power and status" (Machin 2007, 26) ${ }^{32}$ Therefore, this shows that women being powerless are subservient to men and their sexual desires. However, when in an advertisement only images of women are used beside a product e.g. sample 4.6, they have a relatively large image size than the product. The reason is that advertisements not only sell products but also sexuality (Grammer1998, 219-240) ${ }^{33}$ and the concept of sexual commerce, also has contributed to the usage of objectified images of women in order to lure readers into buying the product. Lastly, the use of framing devices does not explicitly objectify women images but add to the meaning. It is mostly done by using framing device of color in order to portray women in a more tempting and eye-catching way.

Apart from visual images; however, verbal language also contributes in objectifying women. For instance, in some advertisements descriptive adjectives and adverbs are used to objectify women such as smart choice, irresistibly soft fragrant skin etc. These words reduce women to the status of commodities who need to look glamorous and enticing. Similarly, in some other advertisements women are treated as objects by associating them with men, and no significance given to their own identity. For example, in sample 4.7 the words used are "Your servant" which associates female participant with the male participant by the use of your, and further decline her status to a servant. Hence, it can be said that visual cues as well as verbal language interact with one another to reinforce the meaning.

\section{Conclusion}

This research explored the ways and means how gender representation is manipulated in Pakistani advertisements. It also facilitated us to study the stereotyped roles of men and women in Pakistani society. One of the social implications of this study is that advertising is not only used to manipulate the customers, but also has a strong influence on shaping attitudes and behavior of people and in disseminating a specific ideology. Through a certain portrayal of a gender in advertisements, people are indoctrinated implicitly with gender stereotypes and language intensifies such representation. These advertisements not only assign certain gender roles, but also promote certain practices in society such as it encourages cosmetic surgeries, size zero and rape culture.

The first question deals with the variety of modes that are employed in advertisements to symbolize women. It was proved that women were presented with different modes of

${ }^{31}$ Goffman, Erving. Gender advertisements. New York: Harper and Row Publishers, 1979, 43.

${ }^{32}$ Machin, David. Introduction to multimodal analysis. London: Hodder Arnold Publication, 2007, 26.

${ }^{33}$ Grammer, Karl. "Sex and gender in advertisements." In Ethnic conflict and indoctrination: Altruism and identity in evolutionary perspective, edited by Irenäus Eibl-Eibesfeldt, Frank K. Salter, 219-240.New York: Berghahn Books, 1998. 
representation, such as a tempting gaze and amorous looks, also sometimes caressing their body or lying on some object to catch the attention of viewers. It is also noticed that in posters where there are men, women are shown subordinate and submissive to them implying male domination. The second research question deals with the language being used on posters that adds to the visual representation of women in an implicit way. The findings show that slogans inscribed on all the advertisements contributed to the objectification of women and their subjugation to male counter parts. Certain modifiers like "smart" and "soft" were used to highlight the sexuality of women. Coming to the third question, this research also helps to create an idea that how our society and its various factors help to shape the representation of women in adverts. Our society being male dominated demands women to act in a conventional way. They are expected to be subservient to men. So, analysis of advertisements in the above section shows that women are being treated as objects while men as powerful and influential figures.

Finally, it can be generalized that portrayal of women in such a manner can be subjected to the gender disparity in Pakistani society. Pakistan has a patriarchal society where women are economically and socially dependent on men. Hence, these disparities lead to a gender-based violence against women including honor-killings, physical and mental abuse, and sexual exploitation. As advertisements tend to be the reflection of a society; thus, women in Pakistani adverts are portrayed as docile and subsidiary through multimodal representation whereas men are depicted as authoritative figures. So, advertising plays a vital role in creating certain stereotypes in the society and influencing people at a large scale.

\section{Bibliography}

Ali, Shahzad and Deeba Shahwar. "Men, women and T.V. ads: The representation of men and women in the advertisements of Pakistani electronic media". Journal of Media and Communication Studies 3(4) 2011: 151-159.

Bardwick, Judith M., and Suzanne I. Schumann. "Portrait of American men and women in TV commercials." In Psychology, 4(4), 1967: 18-23.

Bateman, John. Multimodality and genre: A foundation for the systematic analysis of multimodal documents. Basingstoke: Palgrave Macmillan, 2008.

Collins, Rebecca L. "Content analysis of gender roles in media: Where are we now and where should we go?" Sex Roles 64 2011:290-298.

Courtney, Alice E., and Thomas W. Whipple. "Women in TV commercials." Journal of Communication 24(2) 1974: 110-118.

Gill, Rosalind. "Empowerment/sexism: Figuring female sexual agency in contemporary advertising.' 'Feminism and Psychology 18(1) 2008: 35-60.

Goffman, Erving. Gender advertisements. New York: Harper and Row Publishers, 1979.

Grammer, Karl. "Sex and gender in advertisements."'In Ethnic conflict and indoctrination: Altruism and identity in evolutionary perspective, edited by Irenäus EiblEibesfeldt, Frank K. Salter, 219-240. New York: Berghahn Books, 1998. 
Halliday, Michael A K. Introduction to functional grammar, 2nd ed. London: Arnold, 1994.

Halliday, Michael, and Christian MIM Matthiessen. Halliday's Introduction to Functional Grammar (4 ${ }^{\text {th }}$ edn.). London: Routledge, 2014.

Van Leeuwen, Theo, and Gunther Kress. "Discourse semiotics." Discourse Studies: A Multidisciplinary Introduction. London: Sage Publications, 2011: 107-125.

Kress, Gunther R., and Theo Van Leeuwen. Reading images: The grammar of visual design. New York: Routledge, 2006.

Kress, Gunther R., and Theo Van Leeuwen. Reading images: The grammar of visual design. London: Routledge, 1996.

Machin, David. Introduction to multimodal analysis. London: Hodder Arnold Publication, 2007.

Martin, James R. \& Rose, David. Genre relations: Mapping culture. London: Equino, 2008.

Mirza, Zainab K. and Ifra Iftekhar. "Role of electronic media in preserving gender roles through advertisements". In Proceedings of 2nd International Multi-Disciplinary Conference. Gujrat: The University of Lahore, Gujrat Campus, 2016.

Mirza, Zainab. K. "Male gender stereotypes in Pakistani advertisements". PEOPLE:

International Journal of Social Sciences 2(1) 2015: 1716-1732.

Money, John, and Anke A. Ehrhardt. Man and woman, boy and girl: The differentiation and dimorphism of gender identity from conception to maturity. Baltimore: John Hopkins University Press, 1972.

Serafini, Frank. Reading the visual: An introduction to teaching multimodal literacy. New York: Teachers College Press, 2013.

Stankiewicz, Julie M. and Francine Rosselli. "Women as sex objects and victims in print advertisements". Sex Roles 58 2008:579-589.

Ullah, Hazir. and Hifsa Nisar Khan. "The objectification of women in television advertisements in Pakistan.” FWU Journal of Social Sciences, 8(2) 2014: 26-35.

Van Leeuwen, T. \& Kress, R. Discourse semiotics. In Discourse studies: A multidisciplinary introduction, edited by Van Dijk, Teun A, 107- 125. London: Sage, 2011.

Zotos, Yorgos C. and Eirini Tsichla. "Female Stereotypes in Print Advertising: A Retrospective Analysis". Procedia - Social and Behavioral Sciences 148 2014: 446 454. 
Appendix A

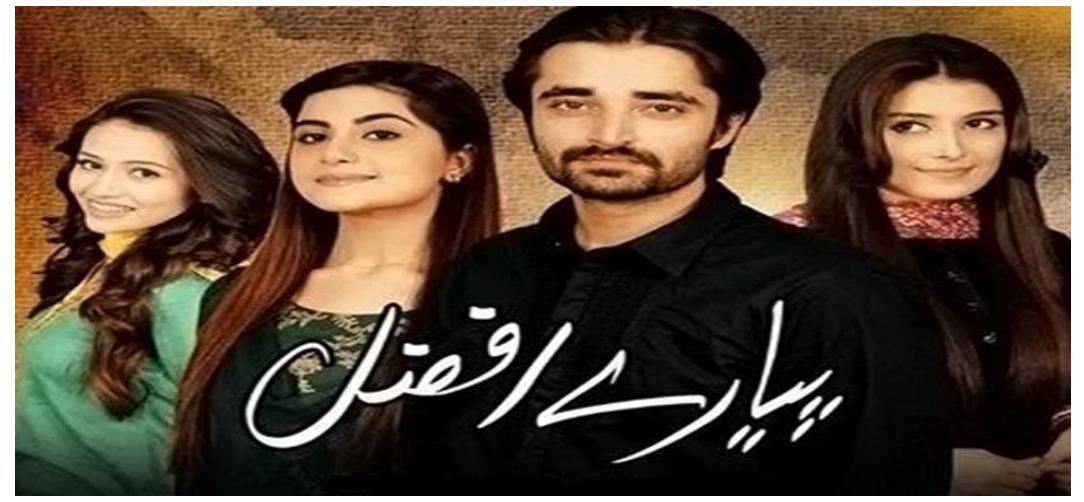

Figure 4.1. Advert of Pyaary Afzal

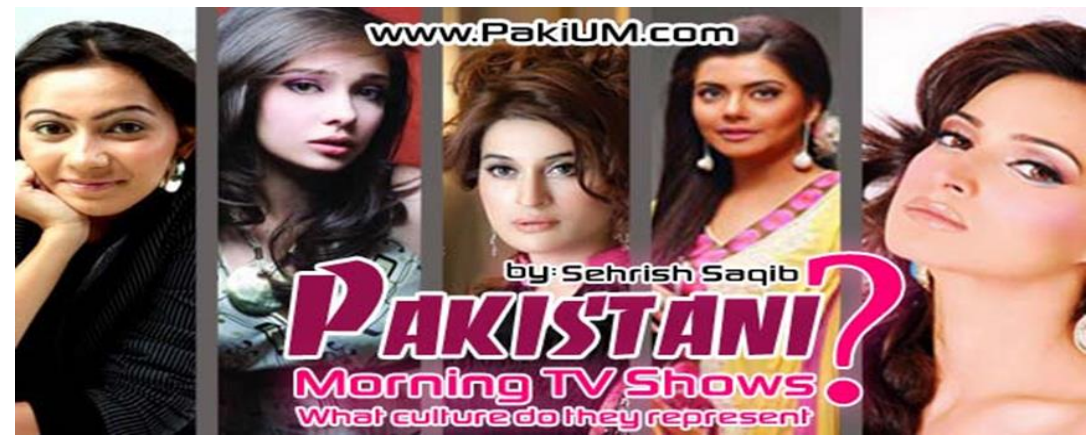

Figure 4.2. Advert of Morning Shows

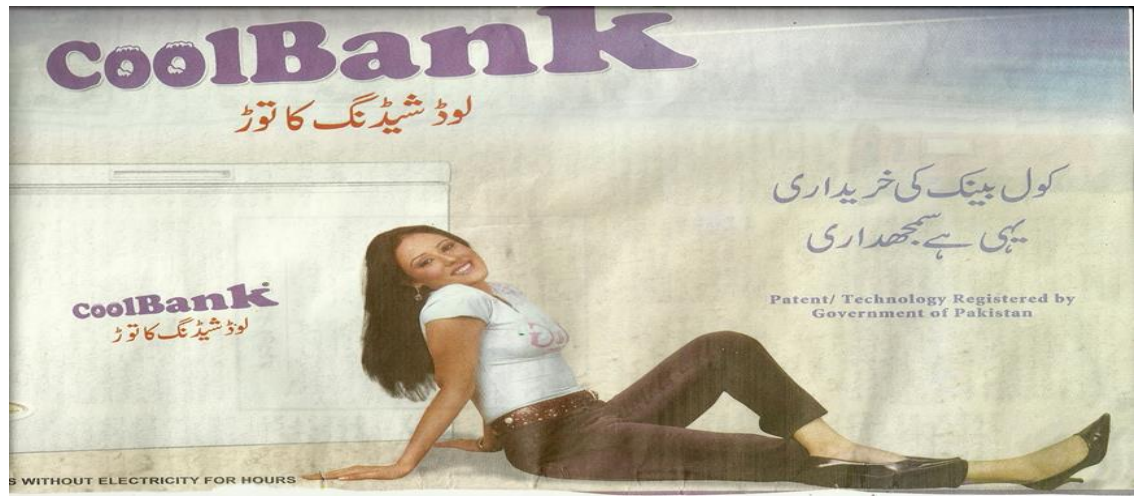

Figure 4.3. Advert of Cool bank Deep Freezer 


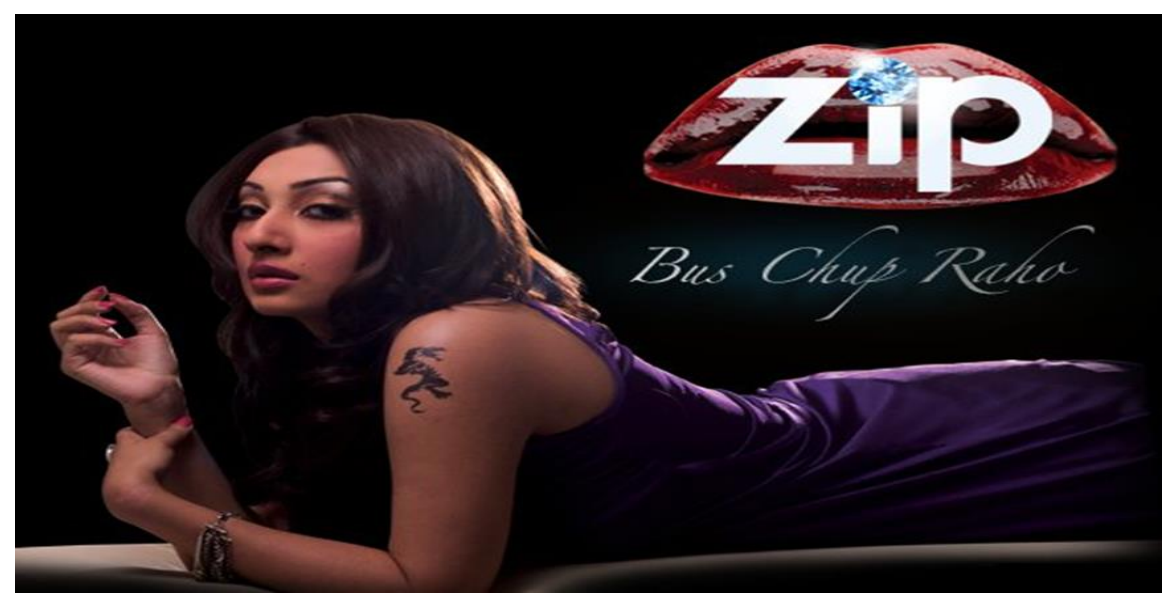

Figure 4.4. Advert of Zip-Bus Chup Raho

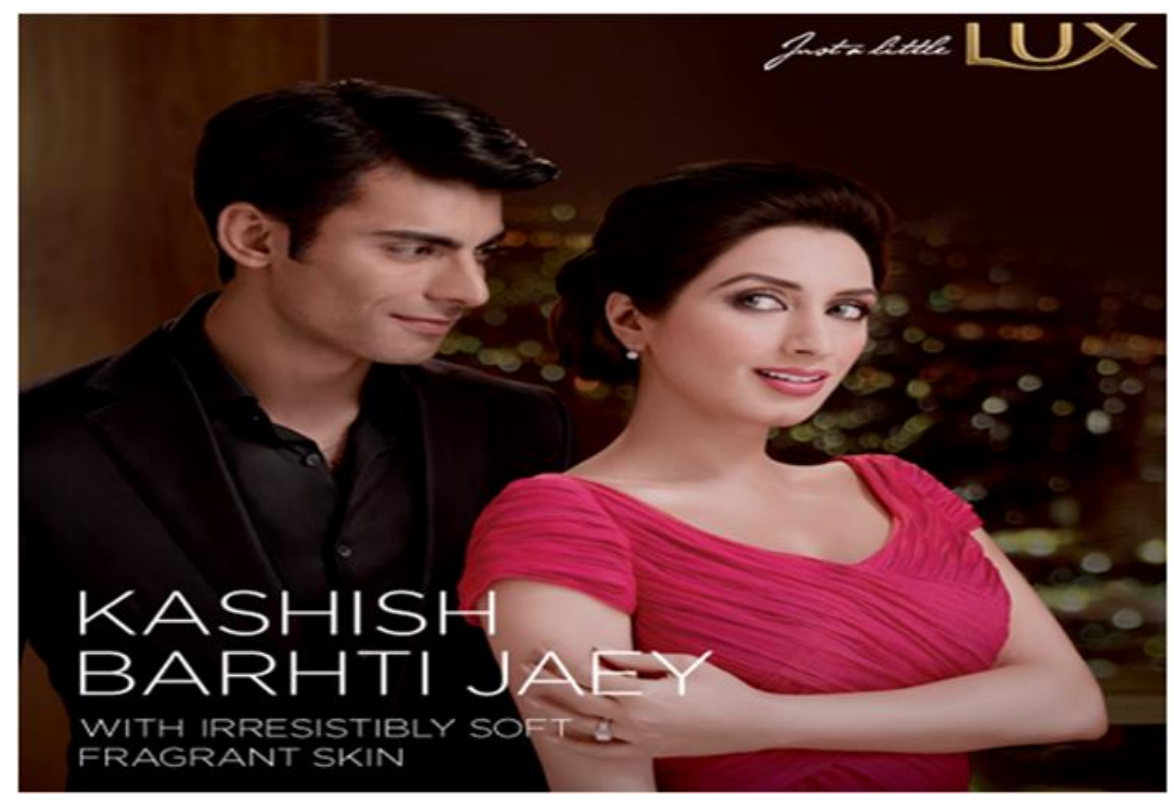

Figure 4.5. Advert of Lux 


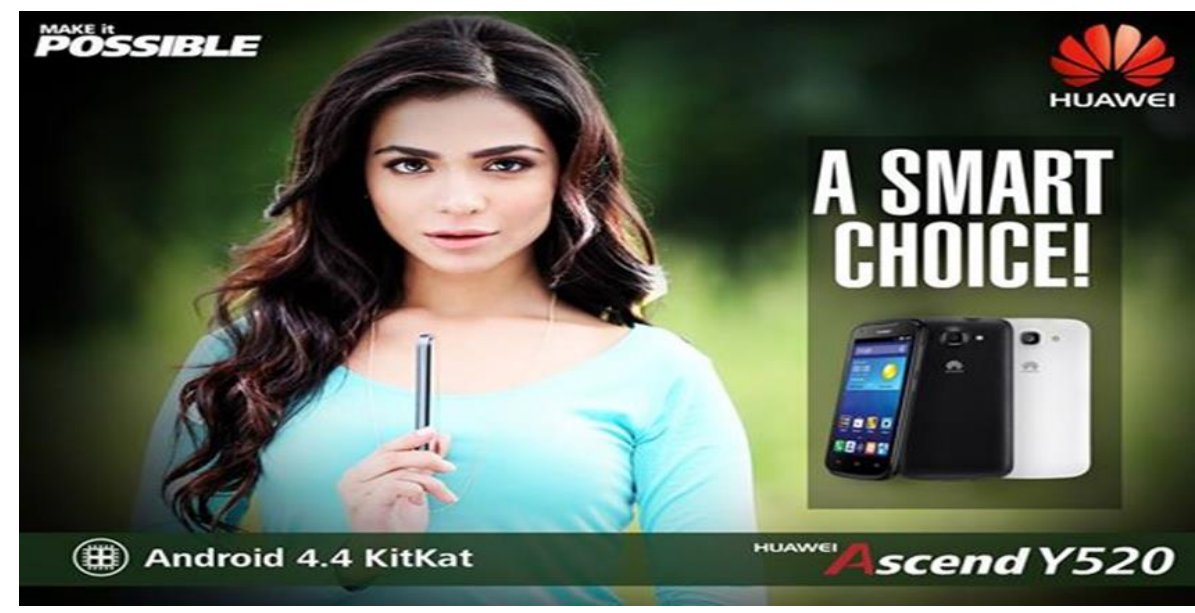

Figure 4.6. Advert of Huawei

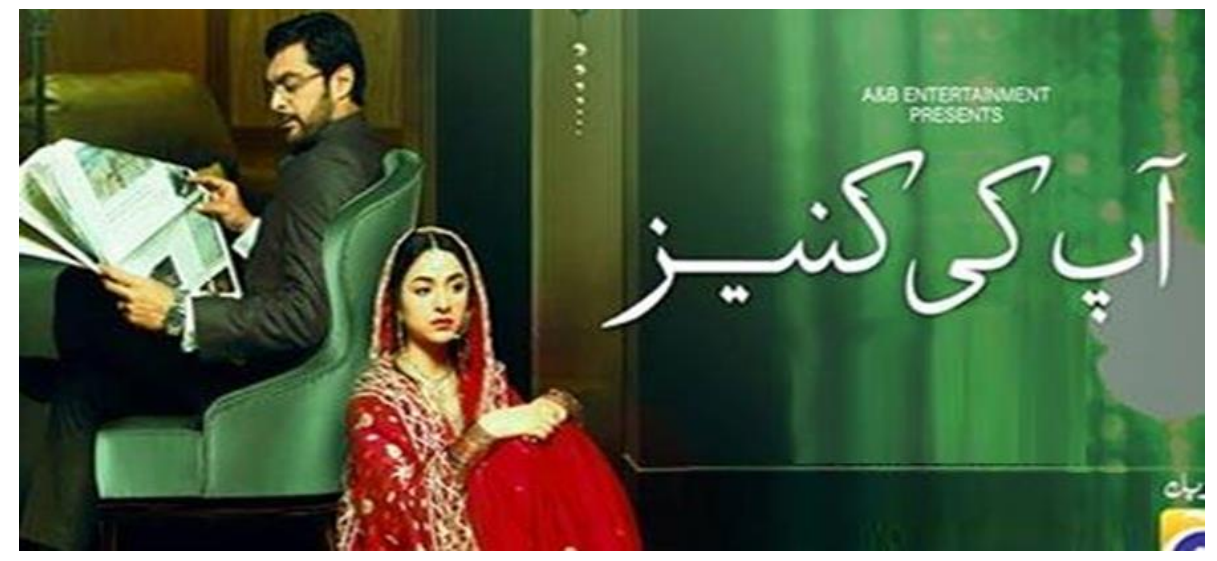

Figure 4.7. Advert of Ap ki Kaneez 